\title{
SISTEMAS DE DISTRIBUIÇÃO E ARRANJOS COOPERATIVOS: O CASO DO ATACADO BRASILEIRO
}

\section{GESTÃO} $\&$ PRODUÇÃO

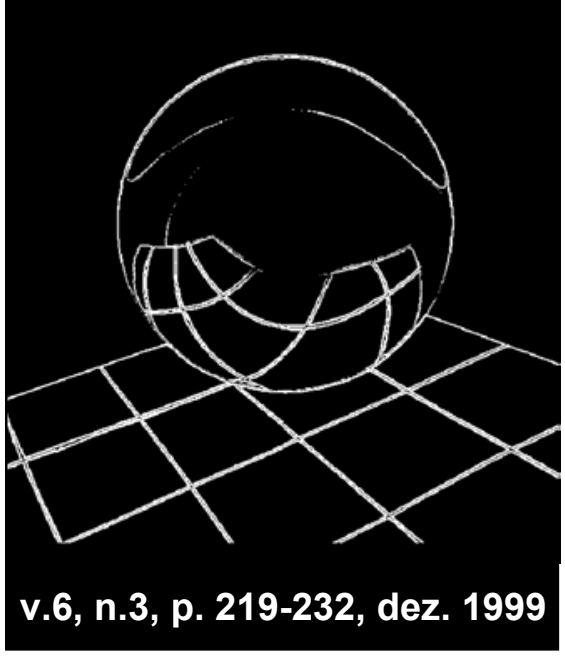

\author{
Rosane L. Chicarelli Alcantara \\ Departamento de Engenharia de Produção \\ Universidade Federal de São Carlos \\ Rod. Washington Luiz, Km 235 - Cx. Postal 676 \\ CEP 13.565-905 - São Carlos - SP
}

\section{Resumo}

Nas últimas décadas uma confluência de eventos tem criado um ambiente de transformação na maneira pela qual os produtos chegam até o consumidor final, o que tem forçado a adoção de uma perspectiva de ação mais cooperativa por parte dos membros dos sistemas de distribuição. Isso porque à medida que o cenário competitivo muda, a forma como as transações são realizadas dentro dos sistemas de distribuição deve acompanhar essa mudança. Visando fornecer sinalizadores que possam guiar as empresas, especificamente os atacadistas distribuidores e seus fornecedores das indústrias de alimentos, higiene, beleza e limpeza, na direção da formação de arranjos mais cooperativos dentro dos seus sistemas de distribuição, esse artigo apresentará os fundamentos estratégicos básicos, as ações a serem desenvolvidas nesse processo de aproximação, as características facilitadoras e limitadoras e os requisitos para a escolha do parceiro.

Palavras-chave: sistemas de distribuição, canais de distribuição, distribuição, bens de consumo, atacado, arranjos cooperativos.

\section{Introdução}

$\mathrm{D}$ e acordo com DROZDOW (1992), se os anos 70 podem ser considerados a década dos produtos e mercados, e os anos 80 a década das finanças, os anos 90 podem ser chamados da década da distribuição. Ganhar, manter e defender o acesso a uma ampla base de consumidores 
está se tornando cada vez mais o foco do pensamento estratégico de empresas cuja filosofia de negócios é orientada ao consumidor. Através das últimas décadas, uma confluência de eventos tem criado um ambiente de transformação na maneira pela qual os produtos chegam até o consumidor final, fazendo com que para muitas empresas o gerenciamento dos seus sistemas de distribuição, e de seus processos, tenha sido alçado à sua lista de prioridades estratégicas.

Dentro desse contexto a gestão dos sistemas de distribuição passa a assumir uma posição de destaque dentro das opções estratégicas das empresas. Porém, à medida que o ambiente competitivo muda, a forma como esses sistemas são gerenciados e suas transações são realizadas também deve acompanhar essa mudança.

Para RINEHART \& PAGE (1992), num ambiente tradicional de negociação as transações entre as empresa dentro do canal de distribuição se baseiam em práticas adversariais, onde a empresa dominante força cada vez mais concessões da outra parte e limita a troca de informações, tudo com a intenção de maximizar seus próprios benefícios, estabelecendo assim uma relação ganha-perde entre as partes. Num ambiente cooperativo ambas as empresas reconhecem que a outra parte exerce um papel necessário e importante no relacionamento, e tendem a trocar informações, as quais acreditam possam torná-las aptas a formação de um arranjo cooperativo pelo qual benefícios mútuos possam ser adquiridos, estabelecendo-se uma relação ganha-ganha.

Para BOWERSOX \& COOPER (1992), a opção pela formação de arranjos cooperativos é a mais adequada em situações de incertezas ambientais, dado que a troca de informações minimiza e divide o risco na tomada de decisões. À medida que os mercados evoluem, os produtos se diversificam e a concorrência se intensifica, os custo para se manter um elevado nível de serviço ao consumidor, pela disponibilização dos produtos no tempo e lugar exatos e em condições de consumo, têm obrigado os fabricantes e os demais membros dos sistemas de distribuição a procurarem estabelecer padrões de relacionamento mais cooperativos.

Visando fornecer sinalizadores que possam guiar as empresas, especificamente os atacadistas distribuidores e seus fornecedores das indústrias de alimentos, higiene, beleza e limpeza, na direção da formação de arranjos mais cooperativos dentro dos seus sistemas de distribuição, esse artigo apresentará as ações a serem desenvolvidas nesse processo de aproximação, suas características facilitadoras e limitadoras e os requisitos para a escolha do parceiro.

A pesquisa, base desse artigo, partiu de duas proposições básicas:

- O novo modelo de relacionamento entre a indústria e os seus distribuidores atacadistas é a formação de alianças ou parcerias, nas quais a tradicional prática adversária de se fazer negócios está dando lugar a um relacionamento mais cooperativo, baseado na confiança mútua entre as partes;

- As chamadas alianças e/ou parcerias existentes entre a indústria brasileira e os seus distribuidores atacadistas ainda são tímidas e pouco estruturadas, podendo necessitar de mecanismos que as tornem mais abrangentes e eficientes.

A partir da proposições adotadas, buscou-se analisar e responder as seguintes questões:

1) Quais são as razões e os objetivos de mercado que levam a essa mudança de comportamento, de uma relação com bases adversariais para uma forma mais cooperativa?

2) Quais são os agentes facilitadores e os limitadores desse processo?

3) Quais os critérios de seleção utilizados na escolha do parceiro?

O método de estudos de caso foi utilizado como forma de se buscar evidências empíricas às proposições adotadas, resultando em generalizações teóricas e não estatísticas sobre a mesma. Múltiplos estudos de caso foram realizados, utilizando-se o par atacado/fornecedor como unidade de análise, dado que isso gera evidências mais determinantes e resultados mais robustos que aqueles advindos de um único caso. A seleção 
dos pares cumpriu duas premissas básicas: os participantes deveriam estar no nível correto dentro do canal, ou seja, indústria e atacado, e estar ativamente envolvidos no processo de desenvolvimento de uma relação mais cooperativa.

Dado a natureza desse estudo, focalizado no relacionamento indústria e atacado com duas características particulares, amostras nãoprobabilísticas foram utilizadas, fazendo-se uso de expert judgment para identificar quais empresas no setor atacadista se encontravam o mais avançado possível nesse processo de mudança. Dentre essas, aquelas que estavam direta e efetivamente envolvidas em relações mais próximas com os seus fornecedores industriais foram selecionadas e formalmente contatadas para participarem da pesquisa, com as seguintes condições:

1) identificar o fornecedor que melhor representava, e com quem melhor se desenvolvia essa aproximação;

2) entrar em contato com o mesmo e requisitar o seu envolvimento na pesquisa;

3) fornecer os contatos que julgava apropriados em ambas as empresas.

Ao serem contatadas, tais empresas receberam um protocolo do estudo de caso contendo informações sobre a pesquisa, seu objetivo e destino, estrutura e participação requisitada. Tal procedimento foi adotado porque a elaboração de um protocolo auxilia muito o pesquisador no desenvolvimento da sua pesquisa, visto que contém as regras de como o estudo de caso será realizado. Esse procedimento facilita e garante a uniformidade na coleta de dados, principalmente em situações de múltiplos estudos de casos.

As informações foram coletadas em: entrevistas com os informantes-chave indicados pelas empresas, documentação fornecida, material público divulgado na imprensa e observações diretas. Foram considerados informantes-chave pessoas envolvidas diretamente nas questões a serem pesquisadas, entrevistados com base em um roteiro de entrevistas não-estruturado, sendo que retornos telefônicos foram utilizados quando necessário.
Foram selecionados para participar dos estudos de caso, de acordo com o exposto acima, os cinco maiores atacadistas distribuidores em faturamento bruto, de caráter nacional ou regional amplo, que juntos totalizam mais de $40 \%$ do faturamento bruto do setor e os 5 fornecedores por eles denominados seus parceiros. Os atacadistas participantes foram: Martins, Arcom, Peixoto, Coselli e Vila Nova. As empresas participantes foram: um fabricante de Produtos de Limpeza Doméstica que solicitou não ser identificado, a Van den Berg Alimentos (Alimentos Industrializados), a Elida Gibs (Higiene Pessoal e Perfumaria), a Loctite (Utilidades Domésticas/Colas e Adesivos), a Colgate Palmolive (Higiene Pessoal e Perfumaria/Limpeza Doméstica) e a Nestlé (Alimentos Industrializados).

A diversidade das empresas participantes, em que cada fornecedor atua na produção e distribuição de produtos diferentes, e cada atacadista distribui uma variedade de produtos com um mix diferenciado e atende diferentes extensões territoriais, permite uma maior generalização dos dados obtidos a outros fornecedores e distribuidores que não diretamente estudados.

\section{Antecedentes}

$\mathrm{D}$ urante décadas, o relacionamento existente entre a indústria, o atacado e o varejo na distribuição de bens de consumo não duráveis vinha se pautando por comportamentos extremamente adversariais. O ponto determinante da negociação era basicamente o preço. À medida que o formato competitivo dentro dos canais de distribuição começou a se alterar em função da estabilização econômica, da crescente globalização dos mercados, do aumento da consolidação da indústria, do uso da tecnologia de informação, do surgimento de formas alternativas de distribuição, da consolidação das grandes cadeias varejistas, da diminuição das margens e do aumento das exigências por parte do consumidor final, empresas líderes no mercado brasileiro, em vários níveis no canal, 
passaram a procurar formas alternativas de agregar valor ao seus produtos.

Essa busca que começou com alterações na arquitetura produtiva, nas instalações físicas e nas práticas gerenciais, basicamente em ações internas, começou a se exaurir forçando as empresas a expandirem suas fronteiras tradicionais e a buscarem em suas relações externas uma solução.

De acordo com SCHMITZ, FRANKEL \& FRAYER (1994), no que tange especificamente a grocery industry, ou seja, empresas que atuam no setor de produtos de mercearia básica como alimentos, higiene, beleza e limpeza, essa busca tem resultado em alterações na administração dos seus sistemas de distribuição, forçando a adoção de uma perspectiva de ação mais cooperativa entre seus membros. Tais alterações têm sido decorrentes de alguns pontos que são discutidos a seguir:

a) As ações oportunistas, tradicionais nas práticas adversariais de negociação, têm forçado empresas a dividirem o controle do canal. Essa ação mais cooperativa é uma tentativa de se evitar que um membro adquira muito poder, reduzindo assim a probabilidade de que este controle informações ou produtos em detrimento dos outros membros do canal;

b) Com um volume de informações cada vez maior a ser processado e analisado, as decisões estão sendo tomadas em bases menos precisas, forçando os tomadores de decisão a restringirem as alternativas na busca de redução da complexidade;

c) Com o aumento das incertezas no mercado as empresas buscam uma maior coordenação nas operações, já que alterações no nível de consumo causam variações na operacionalização de todo o canal, o que exige que a troca de informações seja ampla, confiável e freqüente, o que não é possível no modelo tradicional;

d) A necessidade de investimentos em ativos específicos limita o número de empresas disponíveis a assumirem o risco do negócio.
Uma solução a esses problemas seria a integração vertical, que permitiria à empresa o controle e a coordenação de todo o canal de distribuição pela posse da mesmo. WILLIAMSON (1979), também considera a integralização vertical a decisão mais adequada à empresa nas seguintes situações:

a) Oportunismo: ocorre quando uma empresa visa apenas o seu próprio interesse, não se importando com os prejuízos causados aos demais membros, obtendo seu ganho na diminuição da performance total do canal. Esse tipo de situação é favorecida quando um dos membros sonega ou altera as informações necessárias, deixando os demais membros em desvantagem.

b) Racionalidade Limitada: ocorre quando a quantidade de informação é grande demais para ser efetivamente processada e as decisões resultantes podem ser incompletas ou insatisfatórias. Nesse caso a integração vertical simplifica ou reduz a incerteza do processo pela diminuição do número de alternativas em consideração.

c) Incertezas Ambientais: o aumento das incertezas torna as operações irregulares e os riscos aumentam. A integração vertical possibilita maior coordenação interna e portanto as adaptações necessárias a uma variação inesperada são facilitadas.

d) Fontes de Recursos Limitadas: cria uma situação que encoraja ações oportunistas por parte dos detentores desses recursos. Nessa situação a integração vertical funciona se for capaz de equacionar os interesses envolvidos.

e) Necessidade de Ativos Específicos: reduz o número de alternativas disponíveis devido ao risco do investimento ou a falta de especialização num determinado ativo.

A integração vertical, no entanto, acarreta significativos investimentos financeiros para a empresa e a aceitação do risco associado a esses investimentos, além de obrigá-la a arcar com ativos extremamente especializados, sejam físicos ou recursos humanos, que a torna menos flexível face às mudanças no mercado. A terceirização de 
parte das funções nos sistemas de distribuição pode funcionar como uma alternativa à integração vertical, com a vantagem de diminuir os custos associados a mesma e de aumentar a eficiência com base nos benefícios da especialização. Porém, dois resultados dessa opção são a perda do controle e coordenação das atividades no canal e o aumento do potencial de conflito entre os membros, decorrente das diferenças de objetivos de cada participante.

Tais questões são ainda mais pertinentes na Grocery Industry, empresas que atuam no setor de produtos de mercearia como alimentos, higiene, beleza e limpeza, cuja complexidade inviabiliza, financeira e estrategicamente, a opção pela integração vertical. No caso da opção pela terceirização, permanecendo as tradicionais condições adversariais e de oportunismo, a mesma também resultaria em perdas na performance total do canal. Para SCHMITZ e outros (1994), a formação de arranjos cooperativos dentro dos sistemas de distribuição é uma solução adequada para que essas empresas possam dividir os riscos e os investimentos necessários à complexidade do ambiente competitivo atual, enquanto ampliam suas performances operacional e estratégica, e fornecem maior valor ao consumidor. Também com uma maior comunicação, decisões conjuntas e um real entendimento do papel de cada membro do sistema na criação de valor para o consumidor, os parceiros dessa aliança podem operar de maneira coordenada e diminuir a necessidade de controle.

Isso passa a ser possível com a disseminação tecnológica, que funciona como um agente catalisador do processo, facilitando o fluxo de informações necessárias ao mecanismos de controle e coordenação de um arranjo distributivo descentralizado. $\mathrm{O}$ resultado, segundo MCKENNA (1991), é um sistema de distribuição que integra a empresa, interna e externamente, reduz os problemas de oportunismo e libera os participantes para se preocuparem com a performance total do sistema. Tais alterações também vão de encontro a duas grandes tendências das novas organizações: a eliminação das fronteiras entre as funções gerenciais dentro da mesma organização e a flexibilização da fronteira entre as empresas.

Segundo WEBSTER (1992), ao se buscar melhorar a performance total dos sistemas de distribuição é necessário a criação de modelos focados no relacionamento entre as empresas em questão e, dado ao aumento da importância de relacionamentos cooperativos e de longo prazo entre os membros dos sistemas de distribuição, as empresas devem passar a centrar crescente atenção nas suas habilidades de gerenciar esses relacionamentos. Como habilidades são inerentes a pessoas e não a estruturas organizacionais, essas habilidades podem se tornar o core competency da organização.

\section{Facilitadores e Motivos de Insucesso}

Dara que essa aproximação/cooperação produza os benefícios esperados, tais como redução dos custos e dos riscos, o aumento da sinergia e do serviço ao consumidor, e resultem num ganho competitivo, os membros dos sistemas de distribuição devem estar atentos a fatores que possam de alguma maneira facilitar esse processo. SCHMITZ (1994), FRAYER (1995) e FRANKEL (1995) destacam:

- A tecnologia da informação - comunicação via satélite, EDI (troca eletrônica de dados) ou código de barras facilitam a operacionalização da aliança ao possibilitar trocas de informações mais precisas e em tempo real;

- O ambiente político e legal - a medida que regulamentações excessivas tendem a tornar a cooperação entre empresas uma ação ilegal, medidas de desregulamentação podem ampliar o uso e o alcance das alianças;

- O conceito de logística integrada - responsável pela coordenação das atividades entre as organização, possibilita sua integração pelo controle do fluxo físico de produtos e de informações dentro do canal.

Já a eficácia desses arranjos cooperativos é, de acordo com ACHROL e outros (1990), significantemente melhorada ou diluída pelas atitudes 
e características de seus membros. Alguns pontos específicos a serem avaliados são:

- A compatibilidade organizacional - cada membro possui diferentes ideologias, jargões, hábitos de trabalho, suposições sobre o futuro e preferências por tipos específicos de soluções que podem tornar a aliança difícil de gerenciar. É imperativo que os valores e a cultura das organizações envolvidas sejam compatíveis;

- A compatibilidade de objetivos - o potencial para conflito depende da extensão dos objetivos individuais de cada empresa, e de quanto estes serão sacrificados em função dos benefícios advindos do estabelecimento de objetivos em comum;

- O compromisso organizacional - o compromisso é definido como o desejo e a intenção dos participantes em dar energia e lealdade para que os objetivos e valores do relacionamento sejam efetivamente atingidos, e para sustentar o bem-estar da relação. Membros compromissados são mais cooperativos, comunicativos e flexíveis na resolução de conflitos;

- A confiança - confiança mútua em um relacionamento reduz o desenvolvimento de comportamento oportunístico e portanto diminui a necessidade de mecanismos de controle.

BOWERSOX e outros (1992), consideram que os seguintes fatores adicionais são necessários para garantir o sucesso desse arranjo:

- A divisão de informações - o compartilhamento de informações estratégicas e técnicas é parte vital;

- A especificação dos papéis - esses arranjos ultrapassam, pela sua própria natureza, as fronteiras da organização, com seus membros dividindo os recursos e as facilidades das empresas envolvidas. Em função disso, é necessário que os papéis de cada membro da aliança sejam especificados para que seja possível cobrar responsabilidade e resultados;

- A existência de regras básicas - estabelecem procedimentos claros para as atividades rotineiras e para os eventos inesperados, no dia-a-dia, de forma a evitar problemas e resolver conflitos;

- Os procedimentos para saída - estabelecem parâmetros para a dissolução do arranjo, buscando tornar esse processo menos traumático, o que é muito importante especialmente em situações de elevados investimentos em ativos específicos, além do que um comportamento inadequado poderá colocar em perigo futuros relacionamentos da empresa.

Considerando o fato anteriormente mencionado de que essas aproximações normalmente resultam em arranjos que ultrapassam a fronteira entre as empresas, mas que ao mesmo tempo não possuem organização formal, hierarquia ou identidade legal, ACHROL e outros (1990), colocam que considerações adicionais devem ser feitas para garantir o bom andamento da aliança.

- O papel da liderança - os líderes de cada organização possuem um papel vital no direcionamento e no tom das relações na aliança, e na mediação de políticas internas e externas, portanto devem saber agir diplomaticamente e possuir credibilidade entre as partes;

- A estrutura funcional - embora a forma geral possa ser ditada pelas tarefas e pelo âmbito previsto para a aliança, questões quanto ao grau de centralização ou descentralização das funções, autonomia e/ou integração dos membros, divisão das funções de cada parte, e números de pontos de contatos entre estas, devem ser resolvidas;

- A motivação pessoal - investimentos na motivação das pessoas envolvidas na execução da aliança são fundamentais, pois sem o comprometimento delas muito dificilmente os objetivos propostos serão alcançados.

Segundo SPEKMAN \& SAWHNEY (1990), existem ainda dois fatores que afetam o formato final da aliança:

- Ciclo de vida da empresa - nos estágios iniciais e finais do ciclo de vida da empresa é grande a probabilidade da necessidade da formação de alianças, porque as condições de mercado são relativamente instáveis e a 
estrutura da indústria está mudando tanto em número de competidores quanto em número de produtos. Tais condições aumentam a percepção da vulnerabilidade estratégica da empresa e a formação de alianças oferece uma alternativa competitiva viável nesse cenário;

- Orientação estratégica - ao invés de reagir ao seu meio ambiente, a empresa pode tentar direcionar seu próprio curso de ação e afetar propositadamente esse ambiente. A orientação estratégica da empresa reflete o desejo desta ação em seu ambiente externo, sendo a formação de alianças uma das estratégias possíveis.

Existem limites em quanto uma companhia deve mudar para fazer face às demandas necessárias a essa aproximação cooperativa. $\mathrm{O}$ valor potencial advindo dessa aliança deve ser avaliado e comparado ao valor produzido pela outras atividades da companhia, as quais também demandam recursos. A sua manutenção só deverá ser garantida até o ponto em que essas demandas não sejam conflitantes, e os investimentos necessários não ultrapassem o benefício percebido. Informações adicionais, detalhadas a seguir, enfatizam a importância dos fatores expostos anteriormente.

Uma aliança representa uma forte mudança na forma usual das empresas realizarem seus negócios e nem todas estão preparadas para vencer os obstáculos que tal situação apresenta. Para BOWERSOX e outros (1992), os principais obstáculos são:

- Falta de apoio da alta gerência - para ter sucesso as alianças precisam de comprometimento gerencial, além de financeiro, e muitas vezes os gerentes envolvidos consideram essa nova forma de realizar negócio uma ameaça a suas carreiras. Eles precisam ser esclarecidos quanto ao seu potencial benefício e devem ser convertidos em favor da nova causa;

- Falta de confiança - a dificuldade de construir um ambiente de confiança entre as empresas, acostumadas a negociar em ambiente hostil, atrapalha o processo de troca de informações. A não ser que exista um ambiente propício a troca de idéias e discussões de potenciais soluções, a aliança não irá funcionar;

- Objetivos e metas confusas - cada parte precisa definir claramente qual será o seu objetivo e como irá alcançá-lo, assim como detalhar suas expectativas sobre as responsabilidades das outras partes para que o resultado da aliança possa ser avaliado;

- Compromissos desiguais - alguns membros possuem maiores interesses envolvidos do que outros, e normalmente possuem maior comprometimento com a aliança a longo prazo. Se tal condição os levarem a tirar vantagens adicionais do relacionamento, a confiança e o compromisso entre as partes serão abalados;

- Perda do controle - a não ser que a aliança proporcione ampla comunicação e possua coordenação segura, seus membros não se sentirão seguros em dividir ou perder o controle das funções em favor do sucesso da aliança.

SHERMAN (1992) e SONNENBERG (1992) ponderam que alianças falham porque muitas vezes as empresas se preocupam demais com os ativos físicos necessários, quando o foco deveria ser o entendimento da cultura da empresa e das pessoas envolvidas. O relacionamento dentro da aliança não se restringe apenas aos negócios, trata também do envolvimento entre os parceiros, portanto manter e desenvolver tais contatos faz com que as transações a serem realizadas ocorram num ambiente cordial, com pessoas que se conheçam e se respeitem.

Além disso, os parceiros devem se comportar como iguais dentro do relacionamento, com espírito de cooperação e atenção para as vantagens existentes para todos, pois qualquer sinal de desbalanceamento em favor de um membro pode desestabilizar a relação. Isso, entretanto, não significa que devam dividir todos os procedimentos. A autonomia está emergindo como um dos fatores de sucesso na aliança, pois possibilita que o membro com maior habilidade para determinada função a realize sem que seja necessário consultar os demais parceiros, o que 
torna a aliança mais ágil e eficiente. Além disso, é necessário que a aliança seja flexível às mudanças ambientais. Caso contrário, perderá seu sentido competitivo.

No que diz respeito a situações específicas entre empresas produtoras e seus distribuidores atacadistas, ANDERSON \& NARUS (1990) sugerem 3 mecanismos para neutralizar e resolver as diferenças rapidamente:

- a empresa pode treinar seu pessoal boundaryspanning, a equipe de vendas por exemplo, a ser sensível aos vários tipos de problemas que possam ocorrer e dar-lhe autoridade para resolvê-los logo no início;

- um conselho de distribuidores pode ser criado, servindo como fórum de reclamações, no qual discussões e soluções aceitas por ambas as partes serão desenvolvidas;

- um escritório para um distribuidor ombudsman pode ser criado pela empresa fabricante, sendo esse um distribuidor aposentado com credibilidade entre seus pares, que irá ouvir as suas reclamações e pela sua experiência assessorar o fabricante na busca de uma solução e explicá-la ao distribuidor.

Embora as alianças possuam todo potencial para fazer grandes contribuições ao sucesso competitivo da empresa, é necessário que os riscos associados a esse processo estejam claros. BOWERSOX e outros (1992) consideram que a dependência existente entre os parceiros pode ser considerada um risco inerente ao processo, pois existe sempre a possibilidade de um dos parceiros não atingir a performance desejada. Além disso, como dificilmente todos os parceiros recebem o mesmo benefício da aliança, o membro menos beneficiado poderá ter menos interesse no bem-estar da relação.

Um outro ponto que pode ser considerado é que altos índices de qualidade são normalmente requeridos entre os pares desses arranjos cooperativos, portanto poucos erros e variâncias são tolerados. Outra questão a ser considerada é o risco associado com as oportunidades perdidas em função do arranjo estabelecido. Na verdade, tais arranjos podem ser considerados um paradoxo pois o fato das empresas se fecharem entre si possibilita a concentração de esforços na busca de ganhos coletivos mas, em contraparti$\mathrm{da}$, as expõem ao risco de perderem um pouco do controle do próprio negócio.

\section{O Atacado: Funções e Desafios}

$\mathrm{U}$ ma das mais complexas atividades dentro dos sistemas de distribuição é realizada pelo atacado, que tem como função básica coordenar a produção e o consumo, combinando demandas heterogêneas com suprimentos heterogêneos, tendo de um lado fabricantes interessados em vender toda a sua linha de produtos e de outro varejistas interessados no oferecimento de múltiplas marcas e múltiplas linhas de produto ao seus consumidores finais. Para o fabricante realiza as funções de cobertura de mercado, vendas, estocagem do inventário, processamento de ordens de compra de qualquer volume, pesquisa de mercado e serviço ao consumidor. Em relação aos varejistas oferece disponibilidade de produtos, sortimento conveniente, quantidade de produto adequada à necessidade do varejista, crédito e financiamento, consultoria e suporte técnico.

Embora os atacadistas atuem diretamente na diminuição do gap entre o tempo e o lugar em que os produtos são produzidos e aquele em que são consumidos ou usados, vários analistas de mercado, principalmente na década de 80 , previram que o papel e a importância econômica dos atacadista iria diminuir ou mesmo desaparecer. Tais afirmações estavam baseadas no surgimento e rápido crescimento de grande cadeias varejistas e na tentativa por parte de empresas industriais de realizarem a própria distribuição. Porém, tal cenário não se confirmou por motivos e ações que serão discutidos a seguir.

Em países de economia mais avançada como os Estados Unidos, o setor atacadista está passando por profundas reestruturações que estão resultando em consolidação e mudanças no tipo de administração que, de predominância familiar, está gradualmente se profissionalizando, 
adotando avançadas tecnologias que aceleram a troca de informações e as tornam mais confiáveis. Isto possibilita que diminuam o tempo de operação e melhorem o serviço oferecido. LUSCH e outros (1993) sugerem que os atacadistas que queiram efetivamente se tornar competitivo e resgatar sua posição dentro do canal de distribuição dêem atenção para as seguintes mudanças:

- Fortalecimento das operações centrais reavaliação da sua posição estratégica, centrando esforços no fortalecimento da sua missão central, desfazendo-se das operações marginais, e tornando-se especialistas na distribuição de linhas específicas de produtos;

- Exploração de novos mercados - com a globalização da economia, enormes oportunidades de ação se abrem aos atacadistas que, ao explorarem os novos mercados internacionais, oferecerão aos produtores e varejistas um caminho em expansão para as suas atividades;

- Realizando mais com menos - tecnologia pode cortar custos, aumentar a produtividade, melhorar o gerenciamento das informações e o serviço ao consumidor. Os atacadistas que souberem fazer uso desse potencial estarão em posição de vantagem competitiva no desenvolvimento de relações próximas com fabricantes, varejistas e outros consumidores;

- Compromisso com a qualidade - como uma decorrência natural do aumento da sua preocupação com a satisfação total do consumidor, os atacadistas devem realizar avaliações qualitativa dos seus fornecedores e assumir a função de garantir a qualidade dos produtos distribuídos;

- Orientação ao suporte mercadológico reconhecer que a sua primeira função é ajudar os seus fornecedores e os seus clientes a desenvolverem programas de marketing mais eficiente para o canal como um todo.

Mudanças adicionais na forma de atuação do setor atacadista são discutidas em BOWERSOX \& COOPER (1992):

- Marcas próprias - quase todos os atacadista de sucesso no mercado americano desenvol- veram marcas próprias fortes como uma das formas de ganhar e manter uma posição de vantagem competitiva sustentável;

- Marketing de nichos - alguns atacadistas americanos estão tendo sucesso na distribuição de produtos especializados ou categorias únicas de produtos.

Outro fator a ser discutido como causa das transformações no setor atacadista foi $o$ aparecimento de empresas denominadas de Dominant Buyers ou Power Buyers, originadas na consolidação da indústria varejista americana, cujo exemplo mais conhecido é o Wal Mart. Segundo ROSENBLOOM \& MOLLENKOPF (1993), empresas desse tipo possuem em comum as seguintes características: tendem a ser organizações varejistas de larga escala; possuem substancial poder no canal; atuam mais como compradores para seus consumidores do que como agentes de vendas de seus fornecedores; operam com preços baixos e baixas margens de lucro por unidade de produto; atuam em mercados saturados e portanto brigam por aumentos na sua participação nesse mercado.

Em vista desse fenômeno, os atacadistas precisam entender quais implicações a emergência e o crescimento dos Dominant Buyers exercerá sobre seu papel nos canais de distribuição, para poderem desenvolver estratégias e ações que possam minimizar seu impacto. As principais implicações do surgimento dos Dominant Buyers podem ser:

- Atacadistas colocados fora dos canais de distribuição - o crescimento desse fenômeno poderá resultar em mais atacadistas colocados fora do arranjo distributivo, à medida que aumentar o número de fabricantes que, buscando proteger seus próprios interesses, passem a responder pela demanda de venda direta por parte dos Dominant Buyers;

- Fabricantes e interesses próprios - com uma linha de produtos cada vez mais ampla, em mercados com crescimento desacelerado, os fabricantes brigam ferozmente por espaços maiores na prateleira do varejo, sendo portanto alvo de grande pressão ao negociarem com 
grandes varejistas que controlam enormes segmentos desse mercado;

- Surgimento de atacadistas de larga escala o crescimento a partir de aquisições e fusões e a expansão do território nacional e internacional, possibilitarão aos atacadistas aumentarem sua participação no mercado, aumentarem a produtividade pela economia de escala e investimentos em tecnologia, ampliarem suas bases de fornecedores e portanto oferecerem mais marcas, produtos e serviços aos seus consumidores;

- Desenvolvimento de capacidades - num ambiente de negócios dinâmico, aqueles processos que conectam a empresa com os seus consumidores precisam ajustar-se para encontrar as suas reais necessidades, e o foco da vantagem competitiva hoje está em como as empresas competem, ou quais são as capacidades que dispõem;

- Amparo legal - a prática de compra direta não pode ser considerada ilegal por si mesma, porém há situações em que poderá representar perigo para a livre competição.

Uma outra questão diz respeito a forma de estruturação dos canais de distribuição. Tradicionalmente, os canais de distribuição são estruturados de forma a antecipar o produto em relação a demanda. Esse caráter antecipatório das transações sempre foi visto como um risco necessário e inerente ao processo de adição de valor pela distribuição. No entanto, essa situação pode ser alterada se as empresas envolvidas na distribuição começarem a fazer uso do conceito de Postponement, ou Postergação, cujo objetivo é a redução desse risco. A idéia básica é adiar a configuração final do produto ou sua localização até o momento em que o pedido do consumidor final é recebido. Para que tais ações se concretizem é necessário que o arranjo distributivo seja organizado em torno dessas premissas e, pela sua posição no meio desse sistema, muitas dessas atividades podem ser realizadas pelo atacado, que dessa forma pode ter o seu papel alavancado dentro do sistema.

\section{Resultados e Conclusões da Pesquisa}

$\mathrm{O}$ dados obtidos durante a pesquisa de campo indicam que está ocorrendo um movimento de aproximação entre o atacado distribuidor brasileiro e seus fornecedores, na direção da formação de arranjos cooperativos. Essa aproximação, que é função do crescente aumento da incerteza ambiental, busca minimizar o risco inerente do negócio e a probabilidade do surgimento de ações oportunísticas entre esses membros. Porém, esse processo de aproximação se encontra no início do seu desenvolvimento e as empresas pesquisadas afirmam que a falta de um modelo a ser seguido, que possa ser utilizado como sinalizador dessa mudança e que minimize os custos dos erros decorrentes da mesma, é o grande entrave ao rápido desenvolvimento desse processo.

São apresentados, a seguir, parâmetros de referência sintetizados de ALCANTARA (1997). Espera-se possam servir de guia e base à consolidação dessa nova postura relacional mais cooperativa.

Inicialmente considera-se que as principais razões de mercado que deram início a essa mudança de comportamento entre os atacadistas brasileiros e fornecedores pesquisados, e que são a base a partir das quais as mesmas começaram a se desenvolver, foram: as mudanças na estrutura do varejo, a estabilização econômica, os avanços e a difusão da tecnologia de informação, a abertura da economia, os mecanismos da globalização, a diminuição do ciclo de vida dos produtos, a dificuldade cada vez maior da construção de marcas mundiais, a obsolescência rápida dos processos de produção, um aumento muito grande no número de marcas e produtos disponíveis e as mudanças no comportamento de compra do consumidor. A partir dessas condições ambientais, os atacados pesquisados estão procurando inicialmente construir um posicionamento estratégico calcado nos fundamentos básicos que se seguem:

- Fazer bem o básico: a primeira coisa que deve ser buscada é a excelência no desempenho operacional. $\mathrm{O}$ atacado deve centrar todos os 
esforços para ter performance superior nas 4 funções básicas do seu negócio que são vendas, compras, logísticas e finanças. $\mathrm{O}$ objetivo é reduzir custos, ganhar escala e competitividade nas questões fundamentais. Para tanto terá que profissionalizar sua estrutura administrativa e descentralizar e regionalizar suas operações.

- Aprofundar a relação com os clientes: um caminho possível de crescimento seria ampliar horizontalmente a base de clientes, um outro caminho seria aumentar a penetração nos clientes atuais. Existe um consenso de que a opção mais interessante parece ser estabelecer relacionamentos com maior profundidade em alguns conjuntos de clientes e uma das maneiras de fazer isso é a busca de um modelo próprio. Pode ser interessante desenvolver uma franquia calcada nos novos conceitos de varejo, que se transformaria em uma bandeira e que seria franqueada aos clientes tradicionais interessados. $\mathrm{O}$ atacado entraria como o one source supply mas sem controle societário. Um outro conjunto interessante de clientes a ser desenvolvidos podem ser os chamados clientes VIP, tal como as redes de lojas de conveniência, desenvolvendo acordos de exclusividade de fornecimento de algumas linhas de produto ou de todo o mix. Todas essas ações seriam direcionadas para pequeno e médio varejo.

- Otimizar a composição do mix de produtos e serviços: para sustentar o relacionamento com os clientes seria importante adotar a filosofia full line/full service com descentralização operacional, tanto geográfica como organizacional, indo de encontro à idéia do one stop shopping, numa postura competitiva mais direcionada ao seu cliente. Esse é um padrão diferente do atual do setor atacadista, que na sua maioria tende a atuar com uma linha um pouco mais enxuta, trabalhando com um número restrito de fornecedores e itens, com o objetivo de ser o seu melhor e maior cliente, adotando uma estratégia competitiva mais focada no fornecedor.
- Integrar a cadeia logística: a médio prazo deve-se buscar da integração da cadeia logística, dentro do conceito de cadeia de suprimento (Supply Chain), como opção estratégica para a melhoria do serviço oferecido ao cliente, a otimização da operação e a descentralização da estrutura.

- Especializar e treinar as equipes de compra e venda a partir de sua segmentação em função das linhas ou categorias de produtos, garantindo assim um serviço eficiente, competitivo e ágil, com equipes comprometidas com as necessidades da empresa e dos seus clientes.

- Buscar fornecedores-parceiros cujas características principais sejam: propensão à abertura de informações, comportamento cooperativo, lançamento de produtos inovadores, de alto valor agregado e alto giro, desenvolvimento de ações promocionais conjuntas, entrega de produto paletizado e com código de barra, etc.

- Buscar soluções que minimizem o efeito agravante da carga tributária na formação do preço do produto, dando maiores condições competitivas aos seus clientes.

Paralelo ao desenvolvimento/consolidação desses fundamentos básicos, as ações a serem desenvolvidas por ambas as empresas nesse processo de aproximação, suas características facilitadoras e limitadoras, os requisitos para a escolha do parceiro, compõem os pontos apresentados a seguir.

- Ações a serem desenvolvidas:

1. Procurar conhecer profundamente o parceiro potencial, para entender como funciona o seu processo de negócio e saber para quem esses novos processos serão desenvolvidos;

2. Verificar o grau de precisão e confiabilidade da própria empresa frente ao seu potencial parceiro;

3. Romper as barreiras funcionais, estruturais e culturais existentes dentro da empresa e entre as empresas;

4. Buscar estabelecer um relacionamento multifuncional, não mais restrito às áreas 
de venda da indústria e a de compras do atacado;

5. Buscar encontrar áreas de oportunidade de negócio e começar a trabalhar essas oportunidades, realizando ambas as ações de maneira conjunta com o parceiro;

6. Buscar mecanismos para alavancar a confiança mútua entre as empresas;

7. Buscar uma maior abertura das informações entre as partes, deixando claro que as informações que interessam são aquelas que podem ser traduzidas em oportunidades de negócios;

8. Buscar uma maior aproximação com o parceiro potencial não apenas nas questões relacionadas ao gerenciamento do canal de distribuição, como também em todas as funções relacionadas ao desenvolvimento e promoção do produto e, se possível, nas questões estratégicas e no negócio como um todo;

9. Procurar empresas que possuam compatibilidade organizacional com a sua empresa, a fim de evitar o choque entre culturas muito diferentes;

10.Procurar valorizar a estrutura e o valor que o parceiro pode adicionar ao negócio, deixando claro a importância do mesmo na alavancagem de todo o sistema;

11.Estabelecer objetivos comuns e executáveis, com ganhos claros para ambas as partes;

12. Ter uma postura de aprendizado com o objetivo de gerar conhecimento e divulgálo para o parceiro.

- As características facilitadoras:

1. O uso de tecnologia da informação, à medida que ela possibilita um melhor gerenciamento desse arranjo;

2. A existência de aderência e de sinergia, estratégica e cultural, entre as empresa envolvidas;

3. A busca de um salto qualitativo em termos de estruturação de recursos humanos, investindo muito em treinamento;

4. Uma postura firme e definitiva da alta direção na incorporação dessas mudanças;
5. Um histórico de relacionamento positivo entre as empresas em questão, desenvolvido e melhorado ao longo do tempo, com objetivos sólidos e rentáveis para ambos os lados;

6. O reconhecimento da importância do papel de cada um como agente agregador de valor ao produto no canal;

7. Uma maior integração logística entre as empresas;

8. A estabilidade e a abertura da economia.

- As características limitadoras:

1. Restrições quanto a abertura das informações por falta de confiança na outra empresa;

2. A ausência de um modelo a ser seguido como sinalizador dessa mudança e que minimize os custos dos erros decorrentes da mesma;

3. A não existência de uma base conceitual comum, amplamente desenvolvida e entendida, que possa ser utilizada como uma linguagem comum;

4. A falta desse conhecimento e entendimento faz com que muitas vezes vários conceitos e ferramentas sejam confundidos com a tecnologia de informação que os suportam;

5. Necessidade de grandes investimentos financeiros em ativos específicos e treinamento;

6. Falta de recursos humanos capacitados às novas tarefas;

7. A resistência existente às mudanças necessárias, advinda de uma cultura organizacional estabelecida há vários anos, e de toda uma estrutura de poder gerada dentro das empresas;

8. Estrutura física de transporte e de telecomunicações deficientes.

- Requisitos para escolha do parceiro:

1. Empresas que possuam as estruturas básicas desenvolvidas;

2. Empresas que possuam objetivos estratégicos próximos, se possível já há algum tempo, e que aceitem o comprometimento e o envolvimento com o negócio; 
3. Empresas preocupadas em profissionalizar todo o negócio, em treinar e reciclar a sua estrutura integralmente, e trabalhar com uma visão de negócio de médio e longo prazo;

4. Atacados que sejam focados na distribuição e que trabalhem como agentes incentivadores da demanda;

5. Atacados que trabalhem com um mix e uma variedade que seja compatível com a linha que a indústria oferece;

6. Atacados focados no atendimento aos varejos pequenos e tradicionais, que realmente atuem como complemento da distribuição da indústria;

7. Empresas que estejam sempre dispostas a mudanças, que entendam que existe uma velocidade de mudança, e que a aceitem não como um risco e sim como uma inovação necessária e inerente ao negócio na realidade atual;

8. Empresas que tenham iniciativa de trabalhar em conjunto, verificando onde estão as oportunidades e resolvendo os problemas;

9. Empresas que tenham postura pró-ativa de acreditar que essa é a forma de administrar em conjunto os negócios de uma maneira mais produtiva;

10.Apenas as empresas mais representativas em termos de volume de negócio, ou agregação de valor, deverão ser avaliadas num primeiro momento;

11.A empresa parceira deve ser interessada em conhecer como funciona integralmente a distribuição do parceiro potencial, para poder customizar a sua operação.

Dado que as principais razões de mercado que deram início a essa mudança em direção a arranjos cooperativos dentro dos sistemas de distribuição não são específicas a uma empresa, mas sim compõem o ambiente competitivo atual, pode-se considerar que elas impactam igualmente todas as empresas que nele atuam. Portanto, as ações propostas não devem ser atribuídas a situações particulares de cada uma das empresas pesquisadas e, embora tenham sido obtidas em estudos de caso realizados e estejam diretamente relacionadas a unidade de análise em questão. Avalia-se, portanto, que as ações possam ser utilizadas, de uma forma genérica, por qualquer empresa interessada nesse processo de aproximação como os demais membros do seu sistema de distribuição.

\section{Referências Bibliográficas}

ACHROL, R.S.; LISA, K.S. \& STERN, L.W.: "Designing Successful Transorganizational Marketing Alliances". Marketing Science Institute Report, n. 90 - 118, Sep., 1990.

ALCANTARA, R.L.C.: A Gestão Estratégica dos Canais de Distribuição: Um Exame da Evolução e do Atual Estágio do Relacionamento entre o Atacado de Entrega e a Indústria. São Paulo, Tese de Doutorado. Escola de Administração de Empresas de São Paulo - Fundação Getúlio Vargas, 1997.

ANDERSON, J.C. \& NARUS, J.A.: "A Model of Distributor Firm and Manufacturer Firm Working Partnerships". Journal of Marketing, January, 1990.

BOWERSOX, D.J. \& COOPER, M.B.: Strategic Marketing Channel Management. NY: McGrawHill Inc., 1992.
; DAUGHERTY, P.J.; DRÖGE, C.L.; GERMAIN, R.N. \& ROGERS D.S.: Logistical Excellence - It's not Business as Usual. Burlington: Digital Press, 1992.

DROZDOW, N.: "The Distribution Decade". Chief Executive, issue 74, March, 1992.

FRANKEL, R.: A General Alliance Model: An Examination and Design of Alliances between Manufacturers and Service Suppliers. East Lansing: Michigan State University / Department of Marketing and Logistics, 1995. (Dissertation, Doctor of Philosophy).

FRAYER, D.J.: The Alliance Process: An Examination of Logistic Alliances between Manufacturers and Merchandisers in The Grocery Industry. East Lansing: Michigan State University / Department of Marketing and Logistics, 1995. (Dissertation, Doctor of Philosophy). 
LUSCH, R.F.; ZIZZO, D. \& KENDERDINE, M.: "Strategic Renewal in Distribution". Marketing Management, v.2, n.2, 1993.

MCKENNA, R.: "Marketing is Everything". Harvard Business Review, Jan./Feb., 1991.

RINEHART, L.M. \& PAGE, T.J.: "The Development and Test of a Model of Transaction Negotiation". Journal of Marketing, v.56, October, 1992

ROSENBLOOM, B. \& MOLLENKOPF, D.: "Dominant Buyers: Are They Changing the Wholesaler's Role in Marketing Channels?" In: ROSENBLOOM, B. (Ed.) Wholesale Distribution Channels: New Insights and Perspectives. NY: The Haworth Press, 1993.

SCHMITZ, J.: Design and Evaluation of a General Alliance Model: An Examination of Logistical Alliances Between Manufacturers and Material Suppliers. East Lansing: Michigan State University / Department of Marketing and Logistics, 1994. (Dissertation, Doctor of Philosophy).
; FRANKEL, R. \& FRAYER, D.J.: "Vertical Integration Without Ownership: The Alliance Alternative". Proceedings of The Association of Marketing Theory and Practice, 1994.

SHERMAN, S.: "Are Strategic Alliances working?" Fortune, Sep. 21, 1992.

SONNENBERG, F.K.: "Partnering: Entering the Age of Cooperation". Journal of Business Strategy, 13:3, May/June, 1992.

SPEKMAN, R.E. \& SAWHNEY, K.: "Toward a Conceptual Understanding of the Antecedents of Strategic Alliances". In: Marketing Science Institute Report, n.90-114, August, 1990.

WEBSTER, F.E.JR.: "The Changing Role of Marketing in the Corporation". Journal of Marketing, v.56, 0ct., 1992.

WILLIAMSON, O.: "Transaction-Cost Economics: The Governance of Contractual Relations". Journal of Law and Economics, 22 October, 1979.

\title{
DISTRIBUTION CHANNELS AND COOPERATIVE RELATIONSHIP: THE CASE OF THE BRAZILIAN WHOLESALER
}

\begin{abstract}
In the last decades several events have created different ways for presenting the products to the final consumer, taking a more cooperative approach among the members in the marketing channels. As the competitive scenery changes, the ways of doing transaction within the channel also have to follow. This paper will present guidelines for the wholesalers and their food, hygiene, beauty and cleanliness suppliers on the direction for more cooperative arrangements within their distribution channels.
\end{abstract}

Key words: distribution channels, marketing channels, distribution, consumer goods, wholesalers, relationship management. 